University of Warwick institutional repository: http://go.warwick.ac.uk/wrap This paper is made available online in accordance with publisher policies. Please scroll down to view the document itself. Please refer to the repository record for this item and our policy information available from the repository home page for further information.

To see the final version of this paper please visit the publisher's website. Access to the published version may require a subscription.

Author(s): $\quad$ M. A. Sadeghzadeh, C. P. Parry, P. J. Phillips, E. H. C. Parker, and T. E. Whall Article Title: Issues on the molecular-beam epitaxial growth of $p-S i G e$ inverted-modulation-doped structures

Year of publication: 1999

Link to published version:

http://dx.doi.org/http://dx.doi.org/10.1063/1.123151

Publisher statement: none 


\title{
Issues on the molecular-beam epitaxial growth of $p$-SiGe inverted-modulation-doped structures
}

\author{
M. A. Sadeghzadeh, ${ }^{a}$ C. P. Parry, P. J. Phillips, E. H. C. Parker, and T. E. Whall \\ Department of Physics, University of Warwick, Coventry, CV4 7AL, United Kingdom
}

(Received 28 September 1998; accepted for publication 20 November 1998)

\begin{abstract}
The influence of boron segregation and silicon cap-layer thickness on two-dimensional hole gases (2-DHGs) has been investigated in $\mathrm{Si}_{/} \mathrm{Si}_{0.8} \mathrm{Ge}_{0.2} / \mathrm{Si}$ inverted-modulation-doped heterostructures grown by solid-source molecular-beam epitaxy. Boron segregation, which is significant in structures with small spacer layers, can be suppressed by growth interruption after the boron doping. How growth interruption affected the electrical properties of the 2-DHG and the boron doping profile as measured by secondary ion mass spectroscopy are reported. We report also on the role played by the unpassivated silicon cap, and compare carrier transport at the normal and inverted interfaces. (C) 1999 American Institute of Physics. [S0003-6951(99)04204-7]
\end{abstract}

The $p$-type $\mathrm{Si} / \mathrm{SiGe} / \mathrm{Si}$ modulation-doped (MD) structure is of interest in device physics and in high performance fieldeffect-transistor (FET) applications. ${ }^{1}$ A two-dimensional hole gas (2-DHG) can be formed at the bottom ("inverted") or top ("normal") interface of a $\mathrm{Si} / \mathrm{SiGe} / \mathrm{Si}$ quantum well, provided a Si boron-doped layer is grown at some distance before or after the alloy layer, respectively. The latter case refers to normal MD structures, which have been studied extensively. ${ }^{2,3}$ There are fewer reports on the former arrangement, the so-called inverted MD structures that are more important in device applications. It is well known that in both two-dimensional electron and hole gas systems, the normal MD structures often have higher mobility than inverted ones. The inferior transport parameters of inverted structures have been addressed by considering dopant segregation ${ }^{4}$ and interface roughness. ${ }^{5}$ Moreover, the existence of surface charges, ${ }^{6,7}$ due to surface states on the silicon cap, only affects the conductivity of the two-dimensional carrier gas in inverted structures due to the depletion of carriers in the well. This is avoided in the normal structure by providing an excess concentration of dopant in the doping supply layer. Usually another doped layer is grown near the cap surface of inverted structure to prevent this effect, ${ }^{8}$ but it may cause a second 2-DHG at the normal interface. ${ }^{9}$ Here we report on how the proximity of the surface charges and boron segregation affect the 2-DHG at the inverted interface of $\mathrm{Si}_{0.8} \mathrm{Ge}_{0.2}$ MD structures that have been grown by solid-source molecular-beam epitaxy (MBE).

A critical problem we have addressed is the surface accumulation of boron atoms during MBE growth, ${ }^{10-12}$ which can act as a reservoir source after closing the boron shutter. This can lead to smearing of the leading edge of the doping profile, a reduction or even possible elimination of the spacer and boron doping in the alloy. Boron incorporation during growth interruption was investigated by growing four boron doped layers of thickness $20 \mathrm{~nm}$, concentration 2 $\times 10^{18} \mathrm{~cm}^{-3}$ and separation $55 \mathrm{~nm}$ in silicon on a $p^{++}(001)$ substrate at $575^{\circ} \mathrm{C}$ and at a growth rate of $0.1 \mathrm{~nm} \mathrm{~s}^{-1}$. The

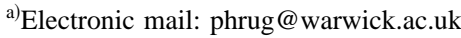

growth was interrupted for 80,40 , and $20 \mathrm{~min}$, respectively, at $5 \mathrm{~nm}$ after closing the boron shutter, but there was no interruption after the final layer. The high resolution secondary ion mass spectroscopy (SIMS) depth profile for boron measured on this structure is shown in Fig. 1. It can be seen that narrow boron spikes (labeled with arrows) have been formed exactly where the growth has been interrupted, indicating the surface accumulated boron atoms, and the sheet density in the spike is higher the longer the interruption. The total measured sheet concentration of boron is the same in each doping layer $\left(3.5 \pm 0.1 \times 10^{12} \mathrm{~cm}^{-2}\right)$, precluding external sources of boron contributing to the narrow spikes observed at the interruptions. The profile also reveals that the integrated sheet density of boron atoms that segregate to dope the pseudo spacer layer after each doping spike/growth interruption, decreases with growth interruption time. These observations suggest that a surface accumulation layer of approximately $1 \times 10^{12} \mathrm{~cm}^{-2}$ of boron atoms forms in each case

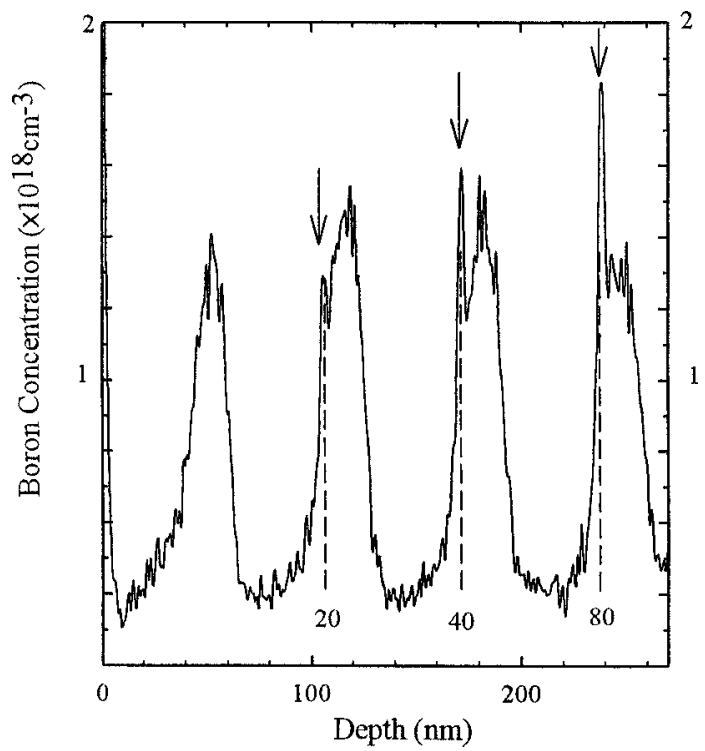

FIG. 1. Boron concentration profile of four $20 \mathrm{~nm} \mathrm{Si}$ boron doped layers separated by $55 \mathrm{~nm} \mathrm{Si}$. Growth was interrupted for 80, 40, and $20 \mathrm{~min}$ at 5 $\mathrm{nm}$ after the first, second, and third doped layers, as shown. (Note the linear B concentration scale.) 


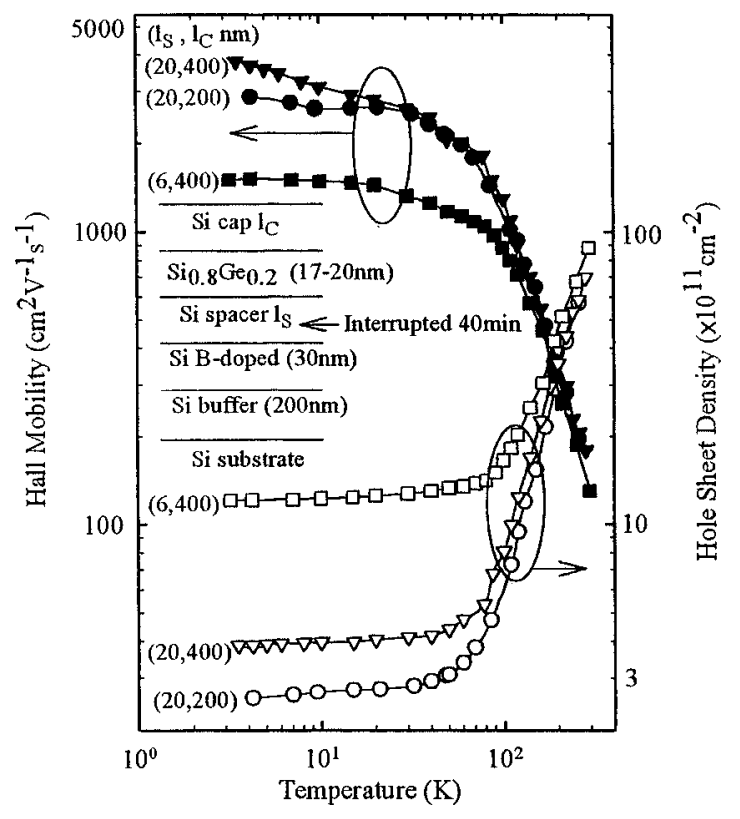

FIG. 2. Hall mobility (filled symbols) and carrier density (hollow) vs temperature for three inverted structures with different spacer $\left(l_{S}\right)$ and cap $\left(l_{C}\right)$ thickness: $l_{S}=20 \mathrm{~nm}$ and $l_{C}=200 \mathrm{~nm}$ (circles), $l_{S}=20 \mathrm{~nm}$ and $l_{C}=400 \mathrm{~nm}$ (triangles), and $l_{S}=6 \mathrm{~nm}$ and $l_{C}=400 \mathrm{~nm}$ (squares).

during the boron doping, but that this is increasingly "stabilized" by growth interruption, so that only a fraction of it segregates to dope subsequently deposited material. The origin of this stabilization phenomenon could be the $\mathrm{C}$ or $\mathrm{O}$ containing impurities that have accumulated on the surface during interruption ${ }^{13}$ - species which are known to inhibit boron diffusion, or due to some reconstruction of the accumulated boron, including clustering. In subsequent experiments we adopted a 40 min growth interruption 3-5 nm after growing doped layer as a compromise practical solution to minimize boron segregation.

The inverted MD structures were grown on $10 \Omega \mathrm{cm}$ $n$-type $\mathrm{Si}(001)$ substrate and consisted of the following layer sequence: $200 \mathrm{~nm} \mathrm{Si} \mathrm{buffer}$ grown at $700{ }^{\circ} \mathrm{C}, 30 \mathrm{~nm} 2$ $\times 10^{18} \mathrm{~cm}^{-3}$ Si:boron doping layer grown at $575^{\circ} \mathrm{C}, 6-20$ $\mathrm{nm}$ Si spacer (dopant setback) grown at $575^{\circ} \mathrm{C}, 17-20 \mathrm{~nm}$ $\mathrm{Si}_{0.8} \mathrm{Ge}_{0.2}$ layer grown at $610^{\circ} \mathrm{C}$, and finally a Si layer of 150 or $400 \mathrm{~nm}$ thickness (see inset to Fig. 2). Normal structures were also grown for comparison, in which the growth temperature was reduced to $610^{\circ} \mathrm{C}$ before growing the alloy, spacer and Si:boron capping layers. Contacts to the 2-DHG were made by $\mathrm{Al}$ sputtering and annealing at $470-520^{\circ} \mathrm{C}$ in a nitrogen atmosphere. Standard Hall bars and Van der Pauw cross shaped devices were prepared by $\mathrm{Si}$ wet etching. Resistivity and Hall effect measurements were carried out for a $500 \mathrm{nA}$ ac current using the lock-in amplifier method at temperatures down to $1.6 \mathrm{~K}$.

The details and measured transport parameters at $4.2 \mathrm{~K}$ of the normal and inverted (denoted by $\mathrm{N}$ and I, respectively) structures, are listed in Table I, and the temperature dependence of the mobility and hole sheet density of three inverted structures is given in Fig. 2. As can be seen, all the samples (including normal structures) had a near constant carrier sheet density $n_{s}$ at $T \leqslant 40 \mathrm{~K}$, indicating a $2-\mathrm{DHG}$ at the respective $\mathrm{SiGe} / \mathrm{Si}$ interface. The inverted structure with a 6 $\mathrm{nm}$ spacer layer and $400 \mathrm{~nm}$ capping layer, (sample B) has Downloaded 14 Jul 2009 to 137.205.202.8. Redistribution subject
TABLE I. The structural and measured $(4.2 \mathrm{~K})$ transport parameters of some of the normal $(\mathrm{N})$ and inverted (I) structures under study.

\begin{tabular}{ccccc}
\hline \hline & $\begin{array}{c}\text { Spacer } \\
l_{S} \\
(\mathrm{~nm})\end{array}$ & $\begin{array}{c}\text { Cap } \\
l_{C} \\
(\mathrm{~nm})\end{array}$ & $\begin{array}{c}\text { Hole } \\
\text { Mobility } \\
\mathrm{cm}^{2} \mathrm{~V}^{-1} \mathrm{~s}^{-1}\end{array}$ & $\begin{array}{c}\text { 2-DHG } \\
\text { Density } \\
\times 10^{11} \mathrm{~cm}^{-2}\end{array}$ \\
\hline Sample I.D. & 4 & & $1950 \pm 100$ & $8.9 \pm 0.2$ \\
$\mathrm{~A}(\mathrm{~N})$ & 6 & 400 & $1550 \pm 100$ & $12.2 \pm 0.2$ \\
$\mathrm{~B}(\mathrm{I})$ & 6 & & $2500 \pm 100$ & $7.2 \pm 0.2$ \\
$\mathrm{C}(\mathrm{N})$ & 20 & & $4330 \pm 100$ & $4.3 \pm 0.2$ \\
$\mathrm{D}(\mathrm{N})$ & 20 & 400 & $3700 \pm 100$ & $4.0 \pm 0.2$ \\
$\mathrm{E}(\mathrm{I})$ & 20 & 200 & 2870 & 2.5 \\
$E^{\prime}$ (etched) & 20 & 150 & $2600 \pm 400$ & $2.6 \pm 0.5$ \\
$\mathrm{~F}(\mathrm{I})$ & 20 & 150 & $4550(\max )$ & $5.2(\max )$ \\
$F^{\prime}$ (gated) & & & &
\end{tabular}

higher carrier density in comparison to that of the normal ones (samples A and C), indicating a reduction of the effective spacer thickness due to the residual boron segregation into the spacer. ${ }^{4}$

Thicker spacer layers $(20 \mathrm{~nm})$ were used in the other samples giving correspondingly lower $n_{s}$ value. However, considering sample E, Poisson-Schrödinger calculations indicate that a higher $n_{s}\left(\sim 5 \times 10^{11} \mathrm{~cm}^{-2}\right)$ than that observed $\left(4 \times 10^{11} \mathrm{~cm}^{-2}\right)$ should be obtained with these sample parameters. This reduction in $n_{s}$ can be attributed to the proximity of the unpassivated surface of the Si cap, where donortype surface states trap holes from the 2-DHG in the SiGe. This was confirmed in sample $\mathrm{F}$ where the thinner $\mathrm{Si}$ cap produced a further reduction in $n_{s}$. Further confirmation was obtained by reducing the cap thickness of sample E using a slow $\left(2.5^{\circ} \mathrm{A} / \mathrm{s}\right) \mathrm{Si}$ etchant to $200 \mathrm{~nm}$, again significantly reducing the $n_{s}$ value. This influence of the Si cap surface could be removed either by passivating the cap surface or by forward biasing a Schottky gate formed on the Si cap. The latter was achieved ${ }^{14}$ in sample $F^{\prime}$ where a Ti/Al gate was sputtered (onto sample F) and forward biased to give a $n_{s}$ value $\left(5.2 \times 10^{11} \mathrm{~cm}^{-2}\right)$ close to the theoretical value in the absence of Si cap influences.

Figure 3 shows how the 2-DHG Hall mobility $\mu$ varies with $n_{\mathrm{s}}$ for all the samples used in this study, including the grown, etched, and gated samples. The apparent universal relationship between $\mu$ and $n_{s}$, irrespective of which interface (N or I) is involved, the cap thickness, and whether the cap surface is unpassivated or gated, strongly suggests that the 2-DHG carrier mobilities at either $\mathrm{SiGe} / \mathrm{Si}$ interface are limited by similar short range scattering processes. ${ }^{15}$ It can therefore be tentatively concluded that there are not large differences between interface roughness, interface charge, and/or alloy scattering at inverted and normal interfaces (all these processes playing a role at $4.2 \mathrm{~K}$ ). The parameters studied merely alter the $n_{s}$ value and do not contribute to carrier scattering.

In conclusion, the effects of boron segregation and cap layer on 2-DHG transport properties have been investigated in $\mathrm{Si} / \mathrm{Si}_{0.8} \mathrm{Ge}_{0.2} / \mathrm{Si}$ inverted-modulation-doped structures grown by solid-source MBE. Boron segregation can be suppressed to an extent by interruption growth after completion of boron doping, by a process possibly linked to the $\mathrm{C}$ and $\mathrm{O}$ impurities which accumulate on the surface during growth interruptions. The unpassivated $\mathrm{Si}$ cap surface traps holes AIP license or copyright; see http://apl.aip.org/apl/copyright.jsp 


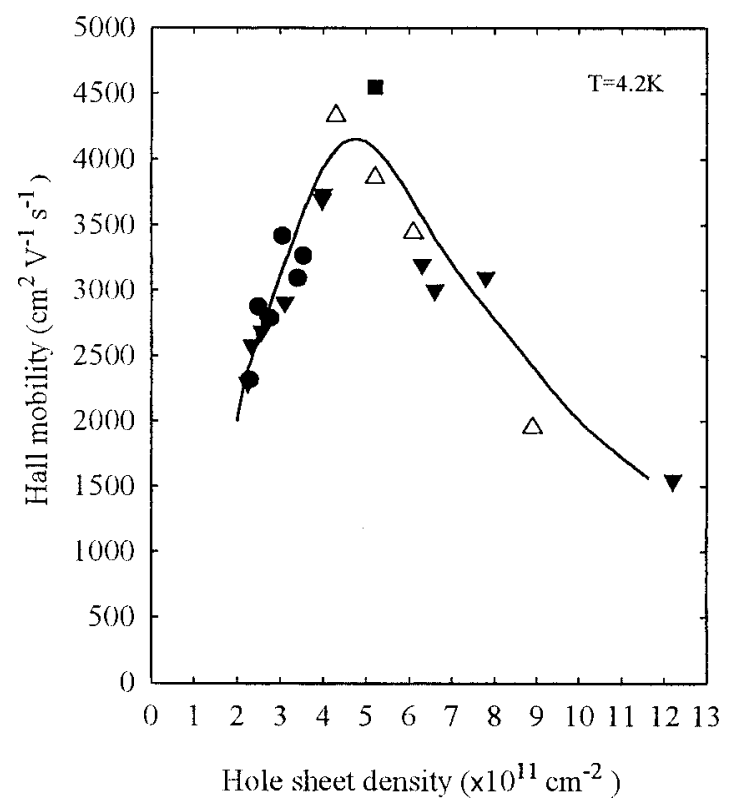

FIG. 3. Variations of the Hall mobility (at $4.2 \mathrm{~K}$ ), vs hole sheet density for all the inverted (filled symbols) and normal (hollow) structures used in this study including: the grown (triangular), etched (circle), and gated (square) samples. The solid line provides a guide for the eye.

from the inverted interface to an extent depending on proximity to it. The study suggests that while carrier sheet density at inverted structures is influenced by boron segregation and cap surface states, the carrier mobility is similar to that of the normal interface and limited by short range scattering processes.

The authors would like to express their gratitude to Dr. Graham Cooke for the SIMS measurements.

${ }^{1}$ U. König and F. Schäffler, Electron. Lett. 29, 486 (1993).

${ }^{2}$ D. W. Smith, C. J. Emeleus, R. A. Kubiak, E. H. C. Parker, and T. E. Whall, Appl. Phys. Lett. 61, 1453 (1992).

${ }^{3}$ E. Basaran, R. A. Kubiak, T. E. Whall, and E. H. C. Parker, Appl. Phys. Lett. 64, 3470 (1994).

${ }^{4}$ T. Mishima, C. W. Fredriksz, G. F. A. van de Walle, D. J. Gravesteijn, R. A. van den Heuvel, and A. A. van Gorkum, Appl. Phys. Lett. 57, 2567 (1990).

${ }^{5}$ U. Meirav, M. Heilbum, and Frank Stern, Appl. Phys. Lett. 52, 1268 (1988).

${ }^{6}$ J. Bardeen, Phys. Rev. 71, 717 (1947).

${ }^{7}$ L. J. Huang and W. M. Lau, J. Vac. Sci. Technol. A 10, 812 (1992).

${ }^{8}$ V. Venkataraman, P. V. Schwartz, and J. C. Sturm, Appl. Phys. Lett. 59, 2871 (1991).

${ }^{9}$ Y. Guldner, J. M. Berroir, J. P. Vieren, M. Voos, I. Sagnes, P. A. Badoz, P. Warren, and D. Dutartre, Phys. Rev. B 48, 12312 (1993).

${ }^{10}$ C. P. Parry, R. A. A. Kubiak, S. M. Newstead, E. H. C. Parker, and T. E. Whall, Mater. Res. Soc. Symp. Proc. 220, 121 (1991).

${ }^{11}$ H. Jorke and H. Kibbel, Appl. Phys. Lett. 57, 1763 (1990).

${ }^{12}$ C. P. Parry, S. M. Newstead, R. D. Barlow, P. Augustus, R. A. Kubiak, M. G. Dowsett, T. E. Whall, and E. H. C. Parker, Appl. Phys. Lett. 58, 481 (1991).

${ }^{13}$ H. J. Osten, G. Lippert, P. Gaworzewski, and R. Sorge, Appl. Phys. Lett. 71, 1522 (1997).

${ }^{14} \mathrm{M}$. A. Sadeghzadeh (unpublished).

${ }^{15}$ R. J. P. Lander, M. J. Kearney, A. I. Horrell, E. H. C. Parker, P. J. Phillips, and T. E. Whall, Semicond. Sci. Technol. 12, 1064 (1997). 